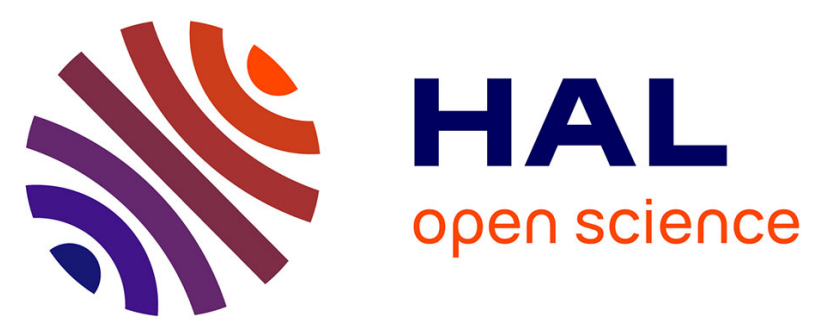

\title{
FANTASIO: a versatile experimental set-up to investigate jet-cooled molecules
}

Michel Herman, Keevin Didriche, Daniel Hurtmans, Baris Kizil, Peter Macko, Atina Rizopoulos, Patrick van Poucke

\section{- To cite this version:}

Michel Herman, Keevin Didriche, Daniel Hurtmans, Baris Kizil, Peter Macko, et al.. FANTASIO: a versatile experimental set-up to investigate jet-cooled molecules. Molecular Physics, 2007, 105 (05-07), pp.815-823. 10.1080/00268970601063820 . hal-00513056

\section{HAL Id: hal-00513056 https://hal.science/hal-00513056}

Submitted on 1 Sep 2010

HAL is a multi-disciplinary open access archive for the deposit and dissemination of scientific research documents, whether they are published or not. The documents may come from teaching and research institutions in France or abroad, or from public or private research centers.
L'archive ouverte pluridisciplinaire HAL, est destinée au dépôt et à la diffusion de documents scientifiques de niveau recherche, publiés ou non, émanant des établissements d'enseignement et de recherche français ou étrangers, des laboratoires publics ou privés. 


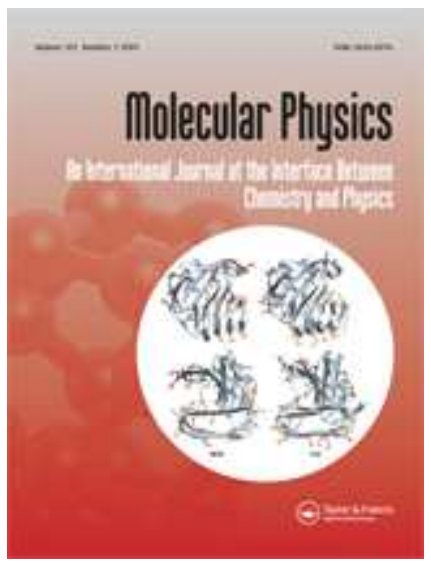

\section{FANTASIO: a versatile experimental set-up to investigate jet-cooled molecules}

\begin{tabular}{|r|l|}
\hline Journal: & Molecular Physics \\
\hline Manuscript ID: & TMPH-2006-0025 \\
\hline Manuscript Type: & Full Paper \\
\hline Author: & $20-$ Sep-2006 \\
\hline Complete List of Authors: & $\begin{array}{l}\text { Herman, Michel; Université Libre de Bruxelles, Chimie quantique et } \\
\text { Photophysique } \\
\text { Didriche, Keevin; ULB } \\
\text { Hurtmans, Daniel; ULB } \\
\text { Kizil, Baris; ULB } \\
\text { Macko, Peter; Comenius University } \\
\text { Rizopoulos, Atina; ULB } \\
\text { Van Poucke, Patrick; ULB }\end{array}$ \\
\hline Keywords: & $\begin{array}{l}\text { jet-cooled molecules, FTIR spectroscopy, Quadrupole mass } \\
\text { spectrometry, CRDS }\end{array}$ \\
\hline $\begin{array}{l}\text { Fig7.OPJ } \\
\text { to PDF. You must view these files (e.g. movies) online. }\end{array}$ \\
\hline \hline
\end{tabular}

\section{今 scholarONE" \\ Manuscript Central}




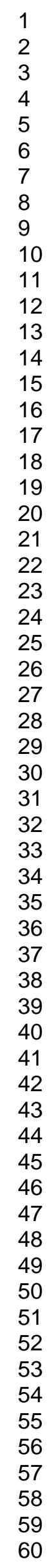

URL: http://mc.manuscriptcentral.com/tandf/tmph 


\title{
FANTASIO: a versatile experimental set-up to investigate jet-cooled molecules
}

\author{
Submitted to Molecular Physics \\ (John Brown's special issue)
}

\author{
M. Herman, K. Didriche*, D. Hurtmans, B. Kizil**,
} P. Macko***, A. Rizopoulos, and P. Van Poucke

Laboratoire de Chimie quantique et Photophysique CP160/09

Université libre de Bruxelles

Ave. Roosevelt, 50

B-1050

Brussels, Belgium

*FRIA Researcher

** FNRS Engineer

*** FNRS and ARC postdoctoral researcher; Permanent address:

Faculty of Mathematics, Physics and Informatics, Comenius University, Mlynská dolina, 84248 Bratislava, Slovakia.

Pages: 25

Figures: 11

Send mail to Prof. M. Herman

Email:mherman@ulb.ac.be 


\section{Abstract}

The design of a new apparatus for studying jet-cooled molecules, named FANTASIO, is described. It includes, around the same supersonic expansion cell, a high resolution Fourier transform spectrometer with single or multipass optics, a tunable diode laser spectrometer with optional cavity ring-down facilities, and a quadrupole mass spectrometer. Performances and operation procedures are illustrated. 


\section{Introduction}

In addition to many high resolution spectroscopic investigations of jet-cooled molecules in the visible spectral region, including those from John Brown (e.g. (1)), a number of studies were dedicated to jet-cooled molecules in the infrared range. The latter used both tunable diode laser (TDL) (see among many others $(\underline{2,3})$ ) and Fourier transform infrared

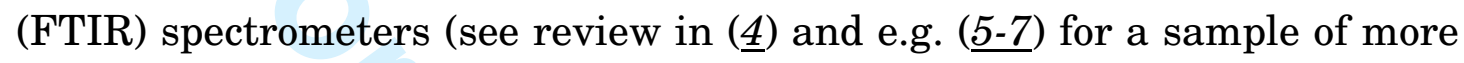
recent papers). The ULB group so far contributed to FTIR-based investigations, exclusively. Following a first generation set-up (ㅎ-10), a more performing system was developed at ULB, with various configurations $(\underline{11,12})$, allowing the vibration-rotation spectrum of several species to be significantly simplified, thanks to both rotational and, for low frequency modes, vibrational cooling. As a result, the vibration-rotation analysis of infrared bands was made possible for a number of stable and less stable species, usually gaseous under standard conditions, namely methane $\left.\left(\mathrm{CH}_{4}\right) \underline{(13}\right)$, dinitrogen trioxide $\left(\mathrm{N}_{2} \mathrm{O}_{3}\right)(\underline{14})$, ethylene $\left(\mathrm{C}_{2} \mathrm{H}_{4}\right)(\underline{15-19})$, dinitrogen tetroxide $\left(\mathrm{N}_{2} \mathrm{O}_{4}\right)(\underline{20})$, acetaldehyde $\left(\mathrm{CH}_{3} \mathrm{CHO}\right)(\underline{21})$, sulfur hexafluoride $\left(\mathrm{SF}_{6}\right)(\underline{22})$, ethane $\left(\mathrm{C}_{2} \mathrm{H}_{6}\right)$ (23-26), 1,2 dichlorethane $(1,2$ $\left.\mathrm{C}_{2} \mathrm{H}_{4} \mathrm{Cl}_{2}\right)$ (27), propene $\left(\mathrm{C}_{3} \mathrm{H}_{6}\right)(\underline{28})$, dimethylether $\left(\mathrm{C}_{2} \mathrm{H}_{6} \mathrm{O}\right)$ (29), propane $\left(\mathrm{C}_{3} \mathrm{H}_{8}\right)(\underline{30})$, and formic acid dimer $\left(\left(\mathrm{HCO}_{2} \mathrm{H}\right)_{2}\right)(\underline{15})$.

We have designed a new set-up, so far only very briefly reported on in the literature (1ㅡ), which we name FANTASIO, for "Fourier trANsform, Tunable diode and quadrupole mAss spectrometers interfaced to a 
Supersonic expansIOn". FANTASIO is presented in this paper and its performances illustrated by a sample of recent results and experimental procedures.

\section{General description of FANTASIO}

In the set-up, the jet is produced vertically from above through either circular or slit nozzles. The circular nozzle we are currently using, in stainless steel, is $500 \mu \mathrm{m}$ in diameter. The slit, in brass, is about $1 \mathrm{~cm}$ long and $30 \mu \mathrm{m}$ wide. All results presented in this work are obtained using one of these nozzles. The gas injection conditions are of continuous type, to match the FTIR sampling characteristics.

The expansion can be monitored in a single, horizontal plane perpendicular to the vertical expansion, using high resolution FTIR, cavity ring-down spectroscopy (CRDS) and quadrupole mass spectrometry (MS). The slit nozzle can be turned around the vertical axis to fit either probe path. The vertical distance separating the nozzle exit from the probe plane can be varied between approximately 5 and $35 \mathrm{~mm}$ by stretching the bellow supporting the nozzle. The reservoir $\left(\mathrm{p}_{0}\right)$ and residual $\left(\mathrm{p}_{\infty}\right)$ pressures are measured using MKS Baratron gauges (1000 and 1 torr full scale, respectively). The studied and carrier gas flows are measured using MKS flowmeters (10000 and $50000 \mathrm{sccm}$ full scale, respectively). 
We use a large turbomolecular pump, Leybold MAG W3200 CT teflon coated, which is backed by an Alcatel ADS 860 HII group. It brings significant changes compared to our previous system based on a $16 \mathrm{~cm}$ long slit nozzle and large Roots blower ( $\underline{15})$. Because of the lower pumping throughput, the amount of material injected in the jet should be now significantly reduced, leading to an undesired decrease in the signal to noise ratio $(\mathrm{S} / \mathrm{N})$. As detailed in sections 3 and 5 this drawback is, however, cancelled thanks to the implementation of more sensitive detection systems than in the previous set-up. On the other hand, more hazardous or less standard gases can now be injected, opening new perspective. For instance acetylene spectra will be reported in the present work, which we did not dare injecting in our previous set-up. Another improvement is that the residual pressure in the absorption cell is dramatically reduced, typically from $10 \mathrm{~Pa}$ down to $1 \mathrm{~Pa}$, for similar reservoir pressures, of the order of $50 \mathrm{kPa}$. The pressure ratio on both sides of the nozzle is therefore now of the order of 50000, i.e. about ten times larger than before. Lower rotational temperatures can therefore be achieved. For instance, for strong bands in standard gases such as acetylene and methane seeded in $\mathrm{Ar}$, some $5 \mathrm{~K}$ can be currently obtained on routine FTIR operation, compared to typically $35 \mathrm{~K}$ previously, with similar $\mathrm{S} / \mathrm{N}$. Given the increase in $\mathrm{S} / \mathrm{N}$ when using the TDL system described in section 5, even lower rotational temperatures could probably be achieved. 


\section{FTIR probe}

The expansion is optically probed perpendicularly to the central flow axis using a FTIR Bruker IFS120HR with maximum available resolution of $0.0043 \mathrm{~cm}^{-1}$ (defined as $0.9 / \delta$, with $\delta$ the maximum optical path difference). This instrumental resolution is the limiting factor when using the slit jet, as further commented on in section 5. It is not when using an axisymmetric expansion. The latter is indeed shaped as a series of concentric divergent cones, with decreasing particle densities as the cone angle increases. Different classes of molecules therefore contribute to high resolution absorption line shapes when optically probing the expansion in a direction perpendicular to the jet axis. These classes are distinct by the cone angle, inducing a specific Doppler shift, and by the particle density, contributing a specific weight to the absorption intensity. As a result, line profiles with FWHM about twice broader than the optimal FT instrumental resolution presently available are observed when probing an expansion produced from the $500 \mu \mathrm{m}$ circular nozzle. This is demonstrated in Fig. 1, which compares the profile of the jet cooled $R(0)$ line in $v_{3}$, pure $\mathrm{N}_{2} \mathrm{O}$, recorded by FTIR using the axisymmetric jet to the Doppler profile calculated at the rotational temperature of the probed gas $(22 \mathrm{~K})$. 
The FT light source, a heated resisting ceramic, is focused onto the entrance iris of the FT instrument. As presented in Fig. 2, the light exiting the spectrometer through the iris is focused using two plane mirrors and a toroidal one $(250 / 40 \mathrm{~mm})$ into the jet chamber. The light is then collected and focused onto an appropriate detector, usually MCT or InSb, using a second toroidal mirror.

Two different optical paths can be selected to probe the expansion. In the first one, a single light pass crosses the expansion as schematized in Fig. 2(top). In this configuration, the cell windows can be set very close to the expansion. Using a $1.5 \mathrm{~mm}$ FTIR iris produces a beam with diameter around $3.5 \mathrm{~mm}$ at the cell windows, with a waist imaging the iris at the centre of the expansion. This configuration, combined with the low residual pressures $\left(\mathrm{p}_{\infty}=1 \mathrm{~Pa}\right)$ strongly limits undesired contribution to the absorption from hot gas surrounding the expansion.

The other optical configuration available in the expansion cell involves multipass optics. Various designs were reported in the FT-jet literature (see $((\underline{4}))$. The present one is schematized in Fig. 2(bottom). The injection optics is identical to the single pass one, but for the focus point now set at the entrance aperture of the multipass system. It is directly inspired from ( $\underline{32})$. It uses two gold coated spherical mirrors each with 50 $\mathrm{mm}$ focal length $(f)$ and separated by a distance of $165 \mathrm{~mm}(d)$. Computer simulations accounting for the resulting ratio $d / f=3.3$ predict some 10 
reflections. The two mirrors are mounted on 4 horizontal aluminum bars set in holders fitting the largest horizontal exits in the expansion cell. When entering a white light beam in the multipass system, a reddish spot is observed in the transmitted beam, due to the specific spectral filtering of the mirrors. Monitoring the reddest focus point allows the optics to be fine tuned and the number of reflections to be estimated. Fig. 3 shows the absorbance spectrum of ${ }^{12} \mathrm{CH}_{4}$ around $3000 \mathrm{~cm}^{-1}$, as recorded without (top) and with (bottom) the multipass optics installed (other, very similar experimental conditions for both recordings are indicated in the caption of Fig. 3). The absorbance shows an increase of a factor of 10.4, while the noise approximately doubles. Therefore the gain is $\sim 5$ on the $\mathrm{S} / \mathrm{N}$. The beam passing straight into the assembly also contributes to the signal, probably explaining the increase slightly larger than the factor 10 expected from the predicted number of reflections. Fig. 3 demonstrates the improvement, both in increasing the $\mathrm{S} / \mathrm{N}$ on $v_{3}, \mathrm{CH}_{4}$, and in making the $v_{2}+v_{4}$ band of this molecule emerge from the noise level on the spectrum around $2850 \mathrm{~cm}^{-1}$. The occurrence of peaks with negative absorbance in the spectra of Fig. 3 will be discussed in section 4 .

The drawback of the multipass system is to spread the infrared beam along the cell which now probes a very large section of the expansion, thus integrating different cooling conditions. Also, the contribution to the spectrum of the residual, hot gas around the expansion is also decupled. A specific procedure will be presented in the next section 
to help removing this undesired contribution. In any case, the multipass system boosts the absorption from jet-cooled molecules, thus canceling the reduction factor due to the decrease in gas throughput due to the turbomolecular pumping compared to the Roots blowers used in our previous set-up previously referred to in section 2 .

\section{MS probe}

MS experiments are performed using a quadrupole mass spectrometer (Hiden RC PIC Analyser-HPR30) interfaced to the jet chamber. As schematized in Fig. 4, it has a retractable sampling probe with circular aperture diameter of about $50 \mu \mathrm{m}$, i.e. small enough to access the local conditions of the probed portion of the flow. The probe moves horizontally, perpendicular to both the jet and the light beam axes. The probe extremity, although also represented as horizontal in Fig. 4, actually faces the vertical jet axis. Molecules travel a long distance in the probe tube before reaching the MS and memory of initial molecular speed is lost before detection. The MS measurements, in counts/s, can separate mass different by one unit, up to mass 510, in amu. The MS uses E2M1.5 rotary and EXT75DX CF63 turbomolecular BOC EDWARDS pumps and channeltron, type detection. The detector has ppm sensitivity. The design of the MS probe is such that it can physically sample only half of the jet cell, from side to center. In the case of an axisymmetric expansion, the 
rotation along the vertical axis of the measured evolution of the mass density from side to center provides a complete horizontal map of the expansion. One can perform additional measurements by moving the nozzle exit up and down, resulting into a 3D picture of the expansion. Similar procedure can be applied to the slit nozzle.

We achieved such a map in a pure $\mathrm{N}_{2} \mathrm{O}$ gas expansion, monitoring the MS signal at mass 30 corresponding to $\mathrm{NO}^{+}$. It is illustrated in Fig. 5 which shows the variation, in function of the vertical nozzle-to probe distance $\mathrm{d}$, of the relative density in the expansion. The density below the nozzle along the central jet axis is close to the expected $1 / \mathrm{d}^{2}$ or $1 / \mathrm{d}$ dependence, for the axisymmetric and slit expansions, respectively. The third, distance axis corresponds to the slit axis in the second part.

A current application of the present MS probe is a procedure to "clean" the infrared spectrum for hot gas contribution. Thanks to the combined mass selection and very high detection sensitivity, one can indeed selectively measure the studied gas density around the expansion, thus the fraction contributing to the residual, hot gas absorption superposing to the jet-cooled spectrum. A similar "hot spectrum" can be later recorded in the same cell without running the large turbomolecular pump, also measuring the gas density. Tuning its intensity to match the relative MS density measurements performed when and without running the jet, one can generate the equivalent "hot spectrum", which can be 
subtracted from the initial jet-cooled one. The procedure is illustrated in Fig. 6. It shows that contribution to the spectrum from hot species is indeed reasonably removed. It is less precise for higher $J$-lines since they are those dominant in the hot gas contribution and minimal in the cold gas absorption. This explains the pseudo negative absorbance in the resulting spectrum, thus after subtraction, already pointed out in section 3. The procedure furthermore neglects potential non linear features depending on the signal intensity. Despite these limitations it was found to be efficient for single pass recordings, in particular. It has been applied to all FTIR spectra presented in this report.

\section{TDL probe}

A diode laser emitting in the $1.5 \mu \mathrm{m}$ range (DFB, ILX lightwave, 1 $\mathrm{MHz}$ linewidth) with InGaAs detector (type PT511, $300 \mu \mathrm{m}$, TO-4G flat window) was coupled to the expansion. We initially used both single pass and multipass optics as described in section 3. Fig. 7 shows multipass TDL spectra of ${ }^{12} \mathrm{C}_{2} \mathrm{H}_{2}$, in $v_{1}+v_{3}$, with $\mathrm{Ar}$ as carrier gas and using the circular nozzle. The subtraction procedure was used to remove the hot gas contribution. The general line profile is typical of the circular nozzle expansion geometry, as already commented on in section 3 . The center dip in $R(0)$ is likely to be indirectly due to the formation of clusters containing acetylene, more efficient along the central jet axis and therefore 
decreasing the amount of absorbing acetylene with zero Doppler contribution, hence at the line center (e.g. $(\underline{33,34))}$. The broad signature of acetylene clusters formed in the expansion was actually observed using the FT probe ( $\underline{35})$, similar to the one presented in ( $\underline{36})$. The decrease of the dip intensity with increasing $J$-values is interesting. One possible explanation is that the clusters are less efficiently bounded when kinetic rotation energy increases as investigated in (그). Clusters would then less and less contribute to the absorption profile, i.e. here to the dip at higher $J$ values, as observed.

CRDS (e.g. (38-41)) was implemented in the set-up, according to the diagram in Fig. 8 and design presented in Fig. 9. It is directly inspired by the developments from the Grenoble group, as detailed in $(\underline{42,43})$. In the present set-up, the DFB diode beam is sent through an optical isolator (Thorlabs 4015 5AFC-APC) and then split by a coupler (Thorlabs, 10 202A-99-APC). Some $1 \%$ of the light intensity is sent with the help of a fiber collimation package $(\mathrm{f}=8 \mathrm{~mm})$ into a home made Fabry-Pérot made of two $50 \%$ reflection flat mirrors positioned on an Invar bar, providing a FSR of about $955 \mathrm{MHz}$. The remaining 99\% of the light are focused by a fiber collimation package $(\mathrm{f}=4.5 \mathrm{~mm})$ onto an acousto-optical modulator (AOM) from AA Opto-Electronic (MGAS 80-A1). The order 1 output from the $\mathrm{AOM}$ is injected into the $\mathrm{TEM}_{00}$ mode of a linear ring-down cavity through a series of two lenses $\left(f_{1}=30 \mathrm{~mm}, f_{2}=50 \mathrm{~mm}\right)$ and two flat mirrors. The cavity is made of two concave mirrors (Radius = $1000 \mathrm{~mm}$; Reflectivity 
$=99.988 \%$ ), separated by about $540 \mathrm{~mm}$. The output coupler is mounted on a piezo system (Piezomechanik HPST 1000/15-8/5). The light exiting the cavity is focused through a lens $(\mathrm{f}=20 \mathrm{~mm})$ on a InGaAs photodiode (type PT511, $300 \mu \mathrm{m}$, TO-4G flat window). The signal from the photodiode is converted by a trans-impedance amplifier (OPA627).

The ring-down detection works as follows. The piezo mount is driven at a selected frequency (typically $500 \mathrm{~Hz}$ ) and cavity mode matching with the laser is achieved at twice the selected frequency. The AOM is switched off as soon as the cavity mode intensity attains a threshold value. The same event triggers the measurement procedure of the ring-down decay. This procedure is controlled by appropriate home made electronics. The ring-down decays are sampled by multifunction data acquisition card PCI-6251, with 16bit $1.25 \mathrm{MHz}$ A/D input. The acquisition is PC driven by home made software written using LabVIEW. Each ring-down exponential decay is fitted by a procedure based on the nonlinear Levenberg-Marquardt method. Typically, some 50 ring-downs per spectral point are fitted and their mean characteristic decay frequency $(\bullet)$ is recorded. The absorption coefficient $\bullet$ is directly calculated using $(\underline{44}):$

$$
\alpha=\left(v-v_{0}\right) \frac{L}{c l}
$$


in which $\bullet_{0}$ is the ring-down decay frequency in an empty cavity (i.e. without absorber), $L$ and $l$ are respectively the lengths of the cavity and the absorption path in the medium and $c$ is the speed of light.

The typical ring-down time is about $15 \bullet \mathrm{s}$, corresponding to some 8333 passes in the $540 \mathrm{~mm}$ long CRDS cavity.

The diode laser frequency can be continuously tuned by sweeping the temperature using a home made PID stabilizer. The temperature tuning from about $60{ }^{\circ} \mathrm{C}$ to $-5^{\circ} \mathrm{C}$ corresponds approximately to the 6544.8 to $6579.3 \mathrm{~cm}^{-1}$ spectral range.

Fig. 10 compares spectra of $v_{1}+v_{3},{ }^{12} \mathrm{C}_{2} \mathrm{H}_{2}$, recorded using a circular nozzle with either FTIR or CRDS. In case of the FT recording, with multipass optics, the acetylene pressure was kept as high as possible within the pumping throughput capacity to increase the $\mathrm{S} / \mathrm{N}$, while it was kept very low to optimize the cooling efficiency when using CRDS, thus leaving room for significantly improved $\mathrm{S} / \mathrm{N}$ in the latter case. The expected sensitivity improvement is striking, calculated to be $\sim 750$ only accounting for the ratio between the effective absorption pathlengths. Residual weaker lines in the CRDS spectrum are mainly from hot bands.

Fig. 11 shows the $R(1)$ line in $v_{1}+v_{3},{ }^{12} \mathrm{C}^{13} \mathrm{CH}_{2}$, in natural abundance $(\sim 2 \%)$. It was recorded under supersonic jet conditions with CRDS using either a circular nozzle (top) or a slit nozzle (bottom), under similar gas flow conditions (see legend of Fig. 11). The top part is actually a blow-up of 
the CRDS spectrum of Fig. 10. The absorption coefficient $\alpha$ is presented in Fig. 11, calculated using Eq. (1). As expected, the line is narrower under slit jet compared to circular nozzle conditions. The FWHM is limited, to $\sim 0.02 \mathrm{~cm}^{-1}$, by geometrical effects when using the nozzle expansion, as detailed in section 2 , while it is instrumentally limited, to $\sim 0.004 \mathrm{~cm}^{-1}$, by the present electronic design when using the slit.

It is interesting to notice that the central dip in $R(1),{ }^{12} \mathrm{C}^{13} \mathrm{CH}_{2}$, is observed when using an axisymmetric expansion, as for the normal isotopologue (see Fig. 7). The absence of dip when using the slit jet could be due to a lack of resolution and/or to the planar nature of the section of the slit expansion probed by the TDL, demonstrating no inhomogeneous molecular behavior.

\section{Conclusion}

In this paper we have presented a new instrumental set-up, named FANTASIO, designed to investigate molecular species in a supersonic expansion. It includes a high resolution FT spectrometer with single and multipass optics, a CRD spectrometer and a quadrupole MS, all interfaced to the same supersonic expansion produced using a large turbomolecular pump backed up by Roots blowers. Various performances of FANTASIO were highlighted, including the MS mapping of axisymmetric or planar 
expansions, the FTIR detection of jet-cooled $v_{2}+v_{4},{ }^{12} \mathrm{CH}_{4}\left(\mathrm{~T}_{\text {rot }}=7 \mathrm{~K}\right)$ using multipass optics, the removal of hot gas contribution in the spectral output of a single pass FT spectrum using MS facilities, and the detection of $R(1)$ $v_{1}+v_{3}$ in ${ }^{12} \mathrm{C}^{13} \mathrm{CH}_{2}$, in natural abundance, using CRDS.

Various limitations were also pointed out, indicating that FANTASIO can be improved in several ways, in terms of resolution for the CRDS detection, in particular. Instrumental advances will be carried on along various lines of developments. In addition, implementation of pulsed nozzles with the present set-up are foreseen with both CRDS and FTIR probes, making profit in the latter case of time resolved FT sampling

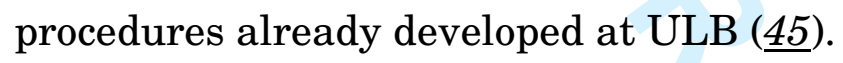

Meanwhile, the investigation of various molecular systems will be undertaken taking advantage of all FANTASIO features.

\section{Acknowledgments}

This paper is dedicated to John Brown for his most significant contribution to our field and for his kind and constant attention to the experimental progresses of the ULB group. 
We are indebted to Prof. R. Georges (U. of Rennes-France) for making possible the construction of the expansion chamber, to Dr. R. Pétry (U. of Giessen-Germany) for providing information on the multipass optics, to Dr. M. Termonia (DMS-Belgium) for helping us to select the mass spectrometer and, at ULB, to Dr. J. Vander Auwera for supporting the FTIR instrument in various occasions and Mr. R. Pétrisse for building some of the equipment.

This work was sponsored by the Fonds National de la Recherche Scientifique (FNRS, contracts FRFC and IISN), the « Action de Recherches Concertées de la Communauté française de Belgique », and ULB research funds. It is performed within the activities of the "LEA HiRes ".

\section{References}

1. A.J. Ross, P. Crozet, R. Bacis, S. Churassy, B. Erba, S.H. Ashworth, N.M.

Lakin, M.R. Wickham, L.R. Beattie, and J.M. Brown, J. Mol. Spectrosc. 177, 134-142 (1996).

2. G. Winnewisser, T. Drascher, T. Giesen, I. Pak, F. Schmülling, and R. Schieder, Spectrochimica Acta, Part A: Molecular and Biomolecular Spectroscopy 55A, 2121-2142 (1999).

3. M.D. Brookes, C. Xia, J. Tang, J.A. Anstey, B.G. Fulsom, K.-X.A. Yong, J.M. King, and A.R.W. McKellar, Spectrochim. Acta A 60, 3235-3242 (2004). 
4. M. Herman, R. Georges, M. Hepp, and D. Hurtmans, Int. Rev. Phys. Chem. 19, 277-325 (2000).

5. A. Bonnamy, R. Georges, E. Hugo, and R. Signorell, Physical Chemistry Chemical Physics 7, 963-969 (2005).

6. P. Asselin, M. Goubet, Z. Latajka, P. Soulard, and M. Lewerenz, Phys. Chem. Chem. Phys. 7, 592-599 (2005).

7. C. Emmeluth, V. Dyczmons, and M.A. Suhm, Journal of Physical Chemistry A 110, 2906 - 2915 (2006).

8. J.K. Holland, M. Carleer, R. Pétrisse, and M. Herman, Chem. Phys. Lett. 194, 175-180 (1992).

9. F. Mélen, M. Carleer, and M. Herman, Chem. Phys. Lett. 199, 124-130 (1992).

10. F. Mélen, M. Herman, G.Y. Matti, and D.M. McNaughton, J. Mol. Spectrosc. 160, 601-603 (1993).

11. R. Georges, G. Durry, M. Bach, R. Pétrisse, R. Jost, and M. Herman, Chem. Phys. Lett. 246, 601-606 (1995).

12. M. Hepp, F. Herregodts, and M. Herman, Chem. Phys. Lett. 294, 528-532 (1998).

13. R. Georges, M. Herman, J.C. Hillico, and D. Robert, J. Mol. Spectrosc. 187, 13-20 (1998).

14. R. Georges, J. Liévin, M. Herman, and A. Perrin, Chem. Phys. Lett. 256, 675678 (1996).

15. R. Georges, M. Bach, and M. Herman, Mol. Phys. 90, 381-387 (1997).

16. M. Bach, R. Georges, M. Hepp, and M. Herman, Chem. Phys. Lett. 294, 533537 (1998). 
17. M. Bach, R. Georges, M. Herman, and A. Perrin, Mol. Phys. 97, 265-277 (1999).

18. M. Bach, R. Georges, M. Herman, and A. Perrin, Mol. Phys. 97, 265-277 (1999).

19. D. Hurtmans, A. Rizopoulos, M. Herman, L.M.S. Hassan, and A. Perrin, Mol. Phys. 99, 455-461 (2001).

20. M. Hepp, R. Georges, M. Herman, J.-M. Flaud, and W.J. Lafferty, J. Mol. Struct. 517-518, 171-180 (2000).

21. I. Kleiner, R. Georges, M. Hepp, and M. Herman, J. Mol. Spectrosc. 192, 228230 (1999).

22. V. Boudon, M. Hepp, M. Herman, I. Pak, and G. Pierre, J. Mol. Spectrosc. 192, 359-367 (1998).

23. M. Hepp, R. Georges, and M. Herman, Chem. Phys. Lett. 275, 513-518 (1997).

24. M. Hepp and M. Herman, Mol. Phys. 94, 829-838 (1998).

25. M. Hepp and M. Herman, J. Mol. Spectrosc. 194, 87-94 (1999).

26. M. Hepp and M. Herman, J. Mol. Spectrosc. 197, 56-63 (1999).

27. Y. El Youssoufi, R. Georges, J. Liévin, and M. Herman, J. Mol. Spectrosc. 186, 239-245 (1997).

28. W.J. Lafferty, J.M. Flaud, and M. Herman, J. Mol. Struct. 780-781, 65-69 (2006).

29. L.H. Coudert, P. Carçabal, M. Chevalier, M. Broquier, M. Hepp, and M. Herman, J. Mol. Spectrosc. 212, 203-207 (2002).

30. J.M. Flaud, W.J. Lafferty, and M. Herman, J. Chem. Phys. 114, 9361-9366 (2001). 
31. M. Herman, K. Didriche, A. Rizopoulos, and D. Hurtmans, Chem. Phys. Lett. 414, 282-286 (2005).

32. R. Petry, S. Klee, M. Lock, B.P. Winnewisser, and M. Winnewisser, J. Mol. Spectrosc. 612, 369-381 (2002).

33. K. Veeken and J. Reuss, Appl. Phys. B34, 149-159 (1984).

34. M. Snels and G. Baldacchini, Applied Physics B: Photophysics and Laser Chemistry B47, 277-82 (1988).

35. V. Vaidyanathan, Y.-C. Lee, Y.-P. Lee, P. Macko, K. Didriche, and M. Herman, Chem. Phys. Lett. submitted for publication, (2006).

36. S. Hirabayashi and Y. Hirahara, Chem. Phys. Lett. 361, 265-270 (2002).

37. C. Boulet, P.-M. Flaud, and J.-M. Hartmann, J. Chem. Phys. 120, 1105311061 (2004).

38. A. O'Keefe and D.A.G. Deacon, Rev. Sci. Instrum. 59, 2544 (1988).

39. J.J. Scherer, J.B. Paul, A. O'keefe, and R.J. Saykally, Chem. Rev. 97, 25-51 (1997).

40. P. Dupre, Comptes Rendus de l'Academie des Sciences; Serie IV: Physique, Astrophysique 2, 929-964 (2001).

41. S. Wu, P. Dupre, and T.A. Miller, Physical Chemistry Chemical Physics 8, 1682-1689 (2006).

42. D. Romanini, A.A. Kachanov, and F. Stoeckel, Chem. Phys. Lett. 270, 538545 (1997).

43. P. Macko, D. Romanini, S.N. Mikhailenko, O.V. Naumenko, S. Kassi, A. Jenouvrier, V.G. Tyuterev, and A. Campargue, J. Mol. Spectrosc 90-108 (2004). 
44. K.W. Busch and M.A. Busch, Cavity-Ringdown Spectroscopy, ed. A.s. series. Vol. 720. 1999, Washington: American Chemical Society. 34-48.

45. S. Kassi, C. Depiesse, M. Herman, and D. Hurtmans, Mol. Phys. 101, 11551163 (2003). 


\section{Figure captions}

Figure 1 (a): Observed jet cooled $\mathrm{R}(0)$ line in $v_{3}$, pure $\mathrm{N}_{2} \mathrm{O}$, recorded by FTIR $\left(\mathrm{p}_{\infty}=0.3 \mathrm{~Pa}, \mathrm{p}_{0}=118 \mathrm{hPa}\right.$, Resolution $=0.0043 \mathrm{~cm}^{-1}, 50$ scans accumulated); (b): Gaussian shaped Doppler line profile calculated for $\mathrm{T}=$ $22 \mathrm{~K}$ and convoluted for various instrumental effects including FTIR resolution $\left(0.0043 \mathrm{~cm}^{-1}\right)$; (c): Straight Gaussian shaped Doppler line profile calculated for $\mathrm{T}=22 \mathrm{~K}$. The amplitude of the two calculated profiles was adapted to match the maximum absorbance of the experimental $R(0)$ line.

Figure 2: FTIR optical paths in the expansion cell further detailed in the text: (top) single pass and (bottom) multipass optics. The same injection optics is used in both configurations but only shown in the top part. It uses two plane mirrors $(\mathrm{Mp})$ and a toroidal one $(250 / 40 \mathrm{~mm})$ $\left(\mathrm{M}_{\mathrm{T}}(1)\right)$ to enter the jet chamber and a second toroidal mirror $\left(\mathrm{M}_{\mathrm{T}}(2)\right)$ to focus the light onto the detector.

Figure 3: Jet-cooled FTIR transmittance spectra of ${ }^{12} \mathrm{CH}_{4}$, with single (top) and multipass (bottom) optics. Flow conditions: $\mathrm{CH}_{4}, 0.36$ 1/min; Ar: 3.6 1/min. Reservoir $\left(\mathrm{p}_{0}\right)$ and residual $\left(\mathrm{p}_{\infty}\right)$ pressures are, for (a): $860 \mathrm{hPa}$ and $1.3 \mathrm{~Pa}$, respectively; and for (b): $847 \mathrm{hPa}$ and 0.4. $\mathrm{Pa}$, respectively. Resolution $=0.0043 \mathrm{~cm}^{-1}, 50$ scans accumulated, $500 \mu \mathrm{m}$ circular nozzle. Hot gas contribution was removed as later illustrated (see Fig. 6). 
Figure 4: Section of the supersonic expansion cell interfaced to the MS with retractable probe in two extreme positions, acting on a bellow. The FTIR beam with single pass optics is also indicated. The expansion, not indicated, is perpendicular to the section of the cell. The probe orifice is actually oriented towards the incoming expansion.

Figure 5: Measured relative $\mathrm{N}_{2} \mathrm{O}$ density along the central vertical jet axis by monitoring the MS signal at mass 30 , corresponding to $\mathrm{NO}^{+}$, at various distances $d$ from the nozzle exit. The density presents a $1 / \mathrm{d}^{2}$ (left) or $1 / \mathrm{d}$ (right) dependence, for an axisymmetric (500 $\mu \mathrm{m}$ circular nozzle; adapted from ( $\underline{31})$, and slit (1 $\mathrm{cm}$ long and $30 \mu \mathrm{m}$ wide slit) expansions, respectively. Flow conditions: for (a) $\mathrm{N}_{2} \mathrm{O} 1 \mathrm{l} / \mathrm{min}, \mathrm{p}_{0}=253 \mathrm{hPa}$ and $\mathrm{p}_{\infty}=0.1$ $\mathrm{Pa}$; for (b): $\mathrm{N}_{2} \mathrm{O}, 1 \mathrm{l} / \mathrm{min} ; 206 \mathrm{hPa}$ and 0.1. Pa.

Figure 6: FTIR transmittance spectra of ${ }^{12} \mathrm{CH}_{4}$, recorded under (top) jet-cooled and (middle) room temperature conditions. For the top spectrum $\left(\mathrm{T}_{\text {rot }}=8 \mathrm{~K}\right)$, flow conditions are: $\mathrm{CH}_{4}, 0.36 \mathrm{l} / \mathrm{min}$; Ar: $3.6 \mathrm{l} / \mathrm{min}$, reservoir $\left(\mathrm{p}_{0}\right)$ and residual $\left(\mathrm{p}_{\infty}\right)$ pressures are $841 \mathrm{hPa}$ and $0.4 \mathrm{~Pa}$, respectively. For the middle spectrum (Room temperature), flow conditions with pure $\mathrm{CH}_{4}$ are $0.007 \mathrm{l} / \mathrm{min}$, with a residual pressure of $1.6 \mathrm{~Pa}$. Resolution $=0.0043 \mathrm{~cm}^{-1}$, 50 scans accumulated, $500 \mu \mathrm{m}$ circular nozzle, multipass optics for both spectra. The intensity of the room temperature data has been tuned to match hot gas density MS measurements performed in both cases, as 
explained in the text. The bottom spectrum was generated by subtraction of the middle spectrum from the top one.

Figure 7: First $\mathrm{R}(\mathrm{J})$ lines in $\mathrm{v}_{1}+\mathrm{v}_{3},{ }^{12} \mathrm{C}_{2} \mathrm{H}_{2}$, recorded under supersonic jet conditions with a circular nozzle and multipass optics, using TDL absorption (flow conditions: $\mathrm{C}_{2} \mathrm{H}_{2} 1 \mathrm{l} / \mathrm{min}, \mathrm{p}_{0}$ and $\mathrm{p}_{\infty}$ are $473 \mathrm{hPa}$ and 0.9 $\mathrm{Pa}$, respectively). A subtraction procedure was applied to remove the hot gas contribution.

Figure 8: Diagram of CRDS detection implemented around the supersonic expansion. Further information is provided in the text. Arrows indicate the light beam and straight lines highlight electronic connections.

Figure 9: Schematic view of the supersonic expansion cell interfaced to the CRDS. The set-up, with all elements detailed in the text, includes a fibered tunable diode laser (TDL) with optical isolator (OpIs), an acousto-optical modulator (OAM), a Fabry-Pérot (F-P), injection optics made of two lenses $\left(\mathrm{L}_{1}, \mathrm{~L}_{2}\right)$ and two planar mirrors $\left(\mathrm{M}_{1}, \mathrm{M}_{2}\right)$, a ring-down cavity made of two concave mirrors $\left(\mathrm{M}_{3}, \mathrm{M}_{4}\right)$ and controlled by a piezoelectric translator $(P Z T)$, a focusing lens $\left(\mathrm{L}_{3}\right)$ and light detectors $\left(\mathrm{D}_{1}\right.$, $\mathrm{D}_{2}$ ). Interfaces to FTS and MS are indicated for completeness. The jet axis is perpendicular to the section of the expansion cell. 
Figure 10: The first $J$ lines in $v_{1}+v_{3},{ }^{12} \mathrm{C}_{2} \mathrm{H}_{2}$, recorded under supersonic jet conditions with a circular nozzle $500 \mu \mathrm{m}$ in diameter using, (top) FTIR with multipass optics, flow conditions are: $\mathrm{C}_{2} \mathrm{H}_{2}, 1.3 \mathrm{l} / \mathrm{min}$; Ar: $1.4 \mathrm{l} / \mathrm{min}, \mathrm{p}_{0}$ and $\mathrm{p}_{\infty}$ are $853 \mathrm{hPa}$ and $1.6 \mathrm{~Pa}$, respectively; (bottom) CRDS, flow conditions are: $\mathrm{C}_{2} \mathrm{H}_{2}, 0.25 \mathrm{l} / \mathrm{min}$; Ar: $2 \mathrm{l} / \mathrm{min}, \mathrm{p}_{\infty}$ is $4.1 \mathrm{~Pa}$. Rotational assignments are indicated on the top spectrum.

Figure 11: The absorption coefficient of the $R(1)$ line in $v_{1}+v_{3}$, ${ }^{12} \mathrm{C}^{13} \mathrm{CH}_{2}$, in natural abundance, recorded under supersonic jet conditions with CRDS: (top) using a circular nozzle, flow conditions are: $\mathrm{C}_{2} \mathrm{H}_{2}, 0.25$ 1/min; Ar: 2 1/min, $\mathrm{p}_{\infty}$ is $4.1 \mathrm{~Pa}$; (bottom) using a slit nozzle, flow conditions are: $\mathrm{C}_{2} \mathrm{H}_{2}, 0.25 \mathrm{l} / \mathrm{min}$; Ar: $2 \mathrm{l} / \mathrm{min}, \mathrm{p}_{0}$ and $\mathrm{p}_{\infty}$ are $633 \mathrm{hPa}$ and 3.9. $\mathrm{Pa}$, respectively. 
1

2

3

4

5

6

7

8

9

10

11

12

13

14

15

16

17

18

19

20

21

22

23

24

25

26

27

28

29

30

31

32

33

34

35

36

37

38

39

40

41

42

43

44

45

46

47

48

49

50

51

52

53

54

55

56

57

58

59

60

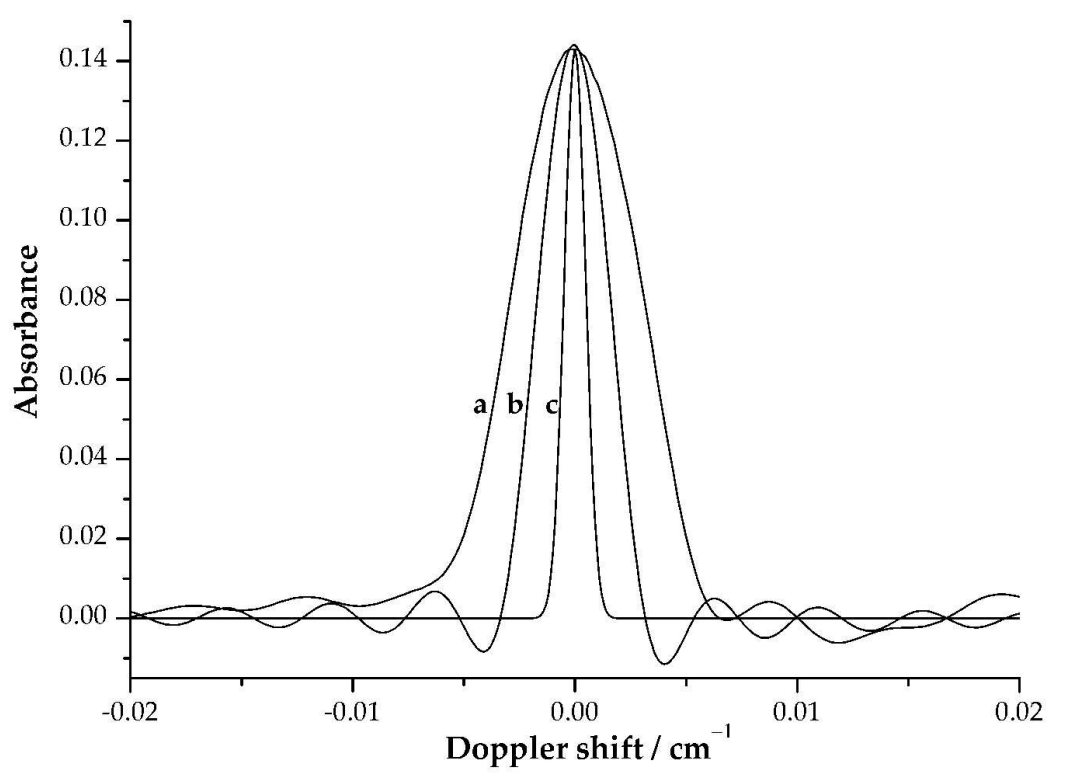

$1184 \times 831 \mathrm{~mm}(72 \times 72$ DPI $)$ 


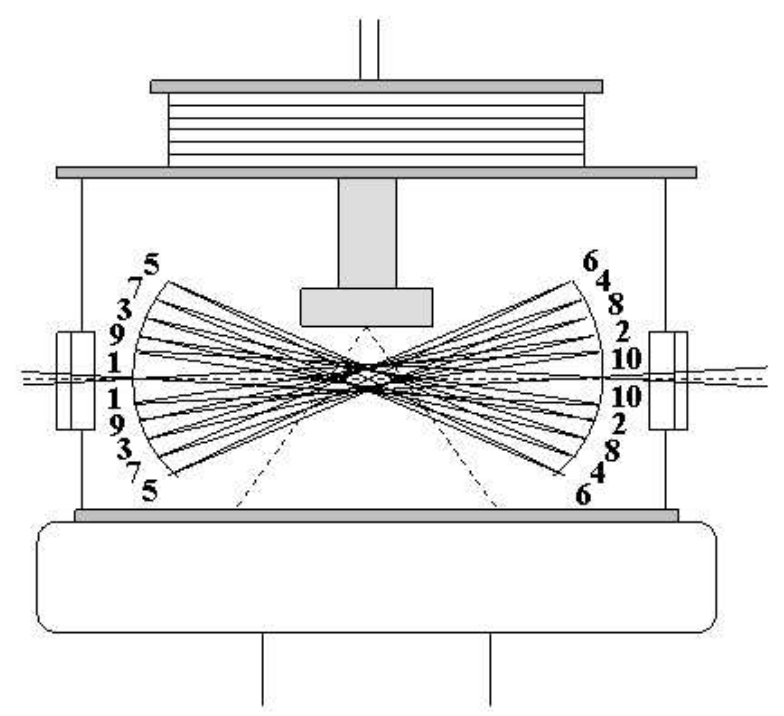

$254 \times 190 \mathrm{~mm}(72 \times 72$ DPI $)$

URL: http://mc.manuscriptcentral.com/tandf/tmph 


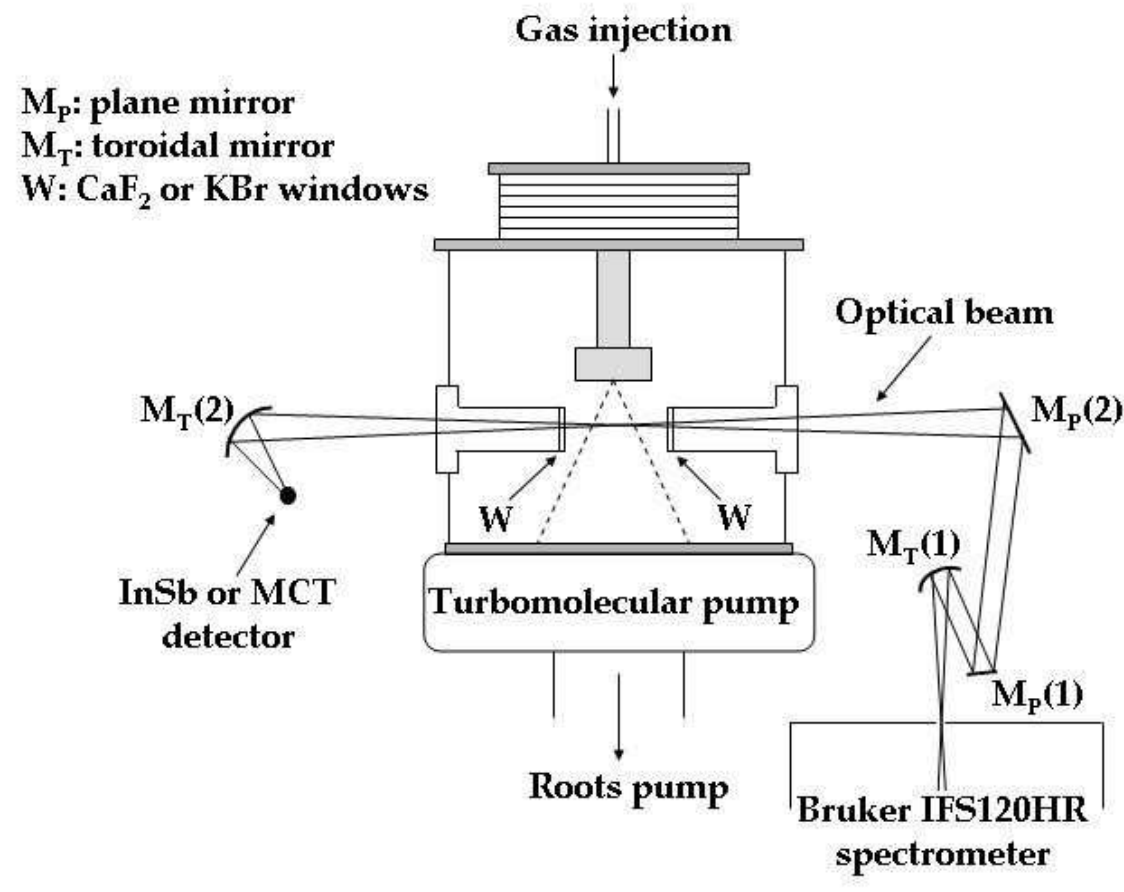

$254 \times 190 \mathrm{~mm}(72 \times 72 \mathrm{DPI})$ 


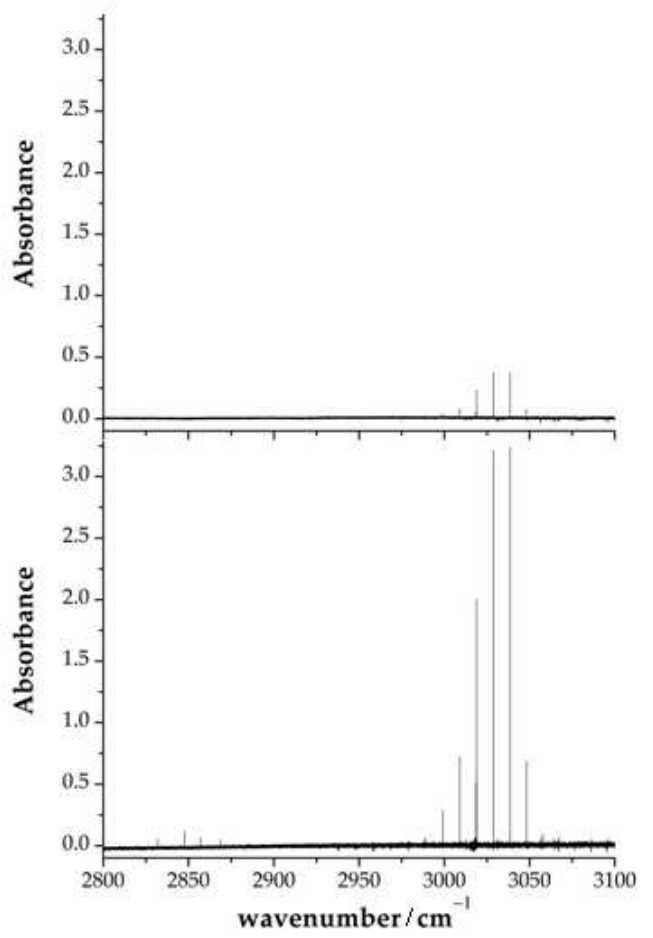

$254 \times 190 \mathrm{~mm}(72 \times 72$ DPI $)$ 


1
2
3
4
5
6
7
8
9
10
11
12
13
14
15
16
17
18
19
20
21
22
23
24
25
26
27
28
29
30
31
32
33
34
35
36
37
38
39
40
41
42
43
40
45
49
50
51
52
53
55
50
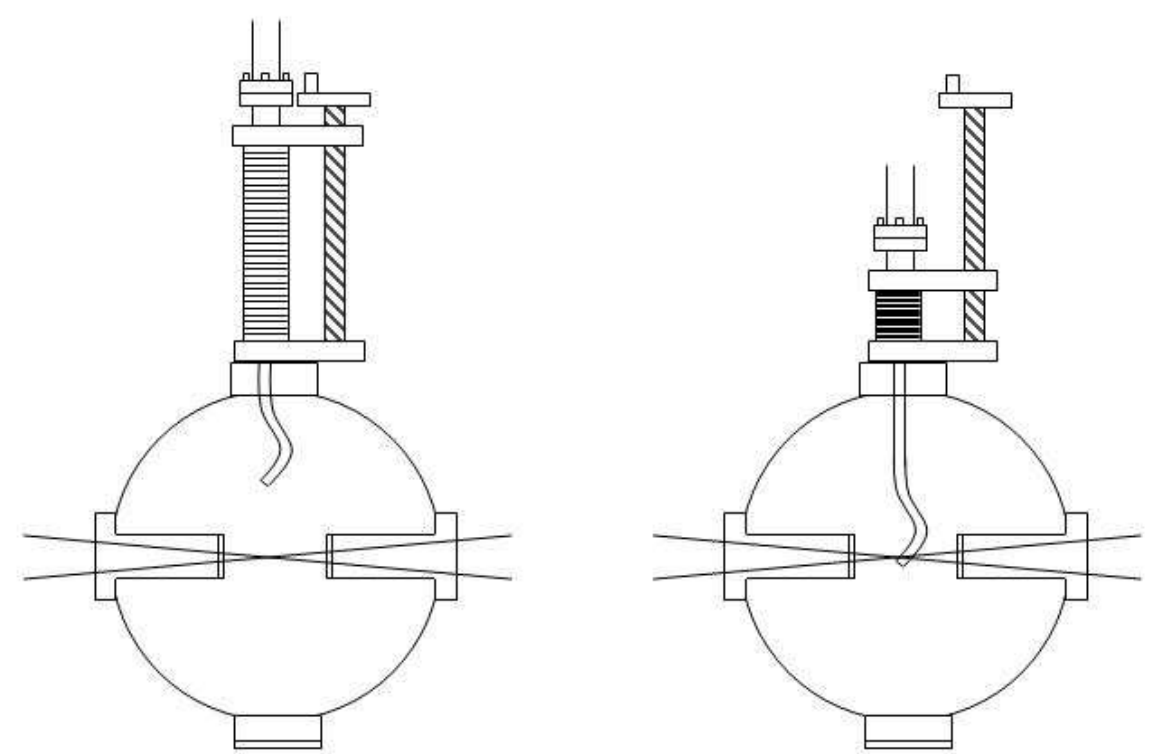

$254 \times 190 \mathrm{~mm}(72 \times 72 \mathrm{DPI})$

URL: http://mc.manuscriptcentral.com/tandf/tmph 


1
2
3
4
5
6
7
8
9
10
11
12
13
14
15
16
17
18
19
20
21
22
23
24
25
26
27
28
29
30
31
32
33
34
35
36
37
38
39
40
41
42
43
44
45
46
47
48
49
50
51
52
53
54
55
56
57
59
60
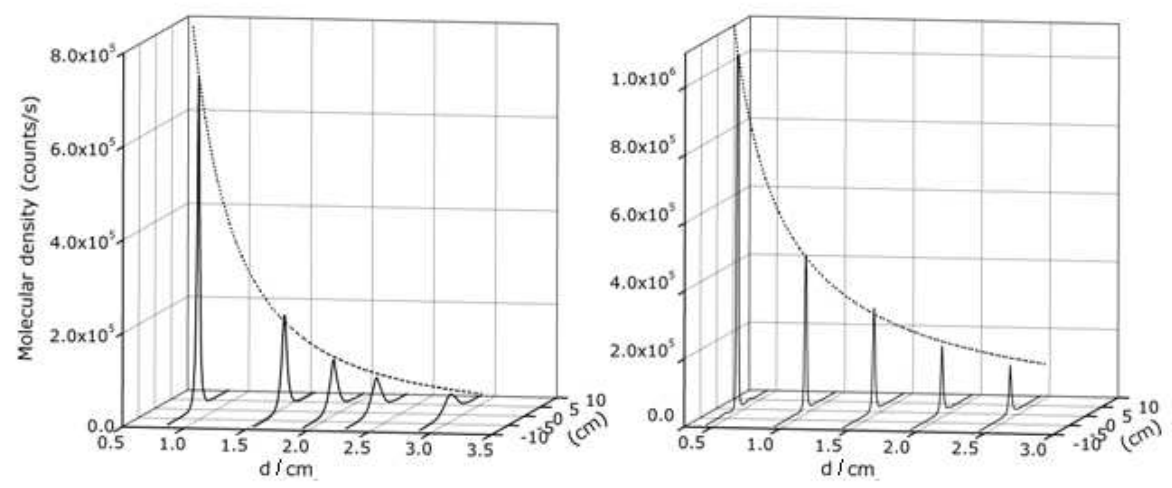

$254 \times 190 \mathrm{~mm}(72 \times 72$ DPI $)$

URL: http://mc.manuscriptcentral.com/tandf/tmph 
1

2

3

4

5

6

7

8

9

10

11

12

14

15

16

17

18

19

20

21

22

23

24

25

26

27

28

29

30

31

32

33

34

35

36

37

38

39

40

41

42

43

44

45

46

47

48

49

50

51

52

53

54

55

56

57

58

59

60

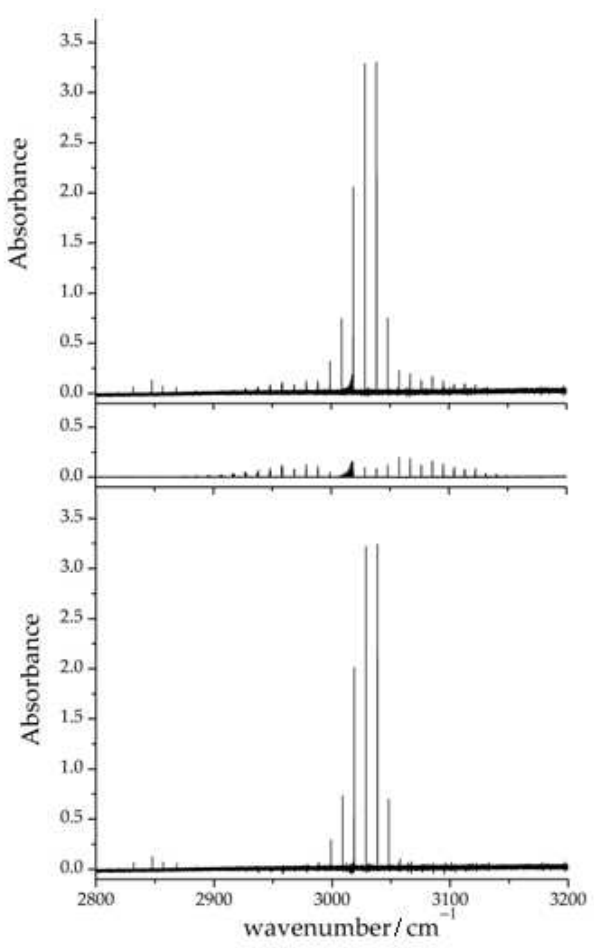

$254 \times 190 \mathrm{~mm}(72 \times 72 \mathrm{DPI})$ 


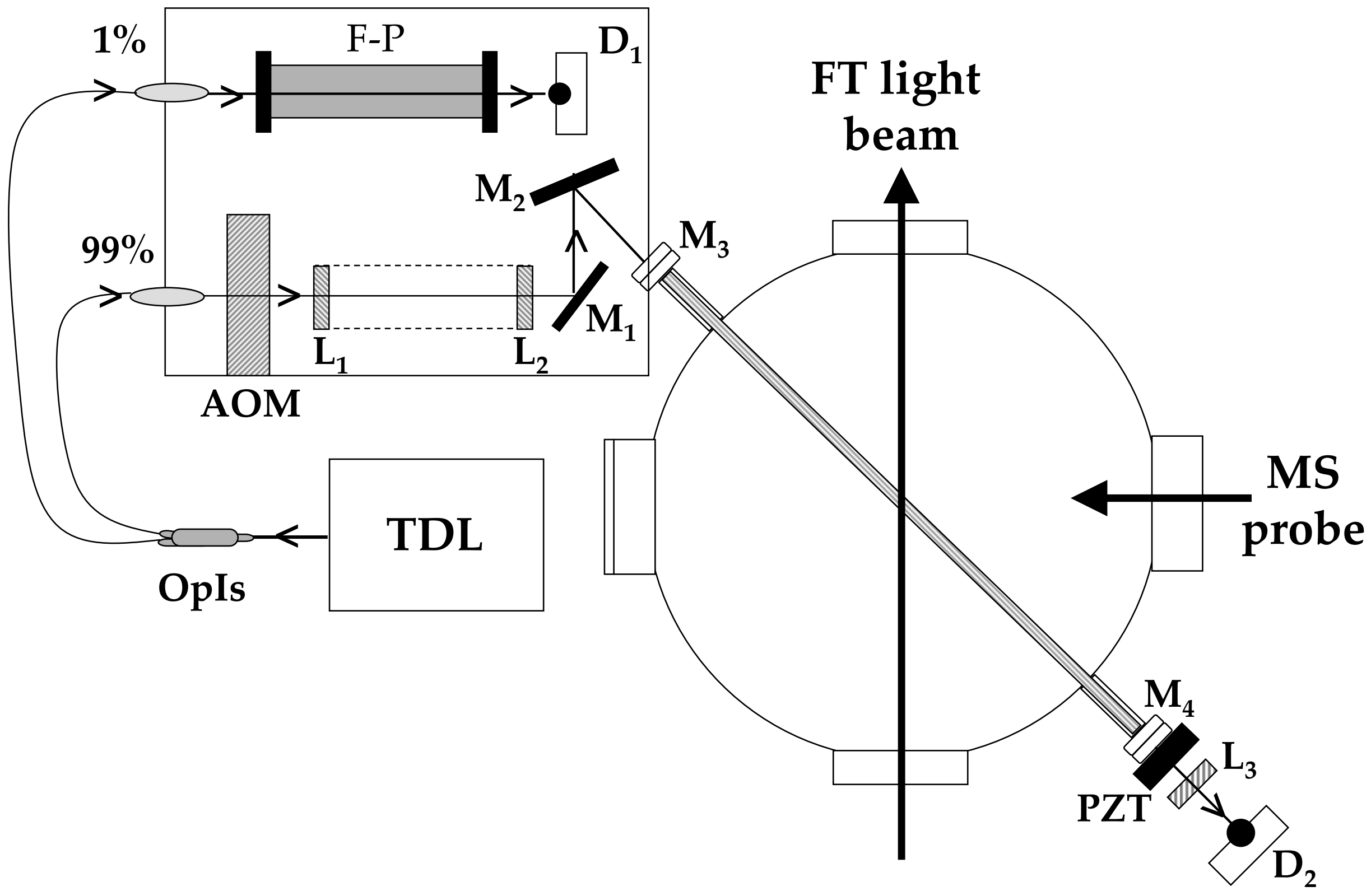




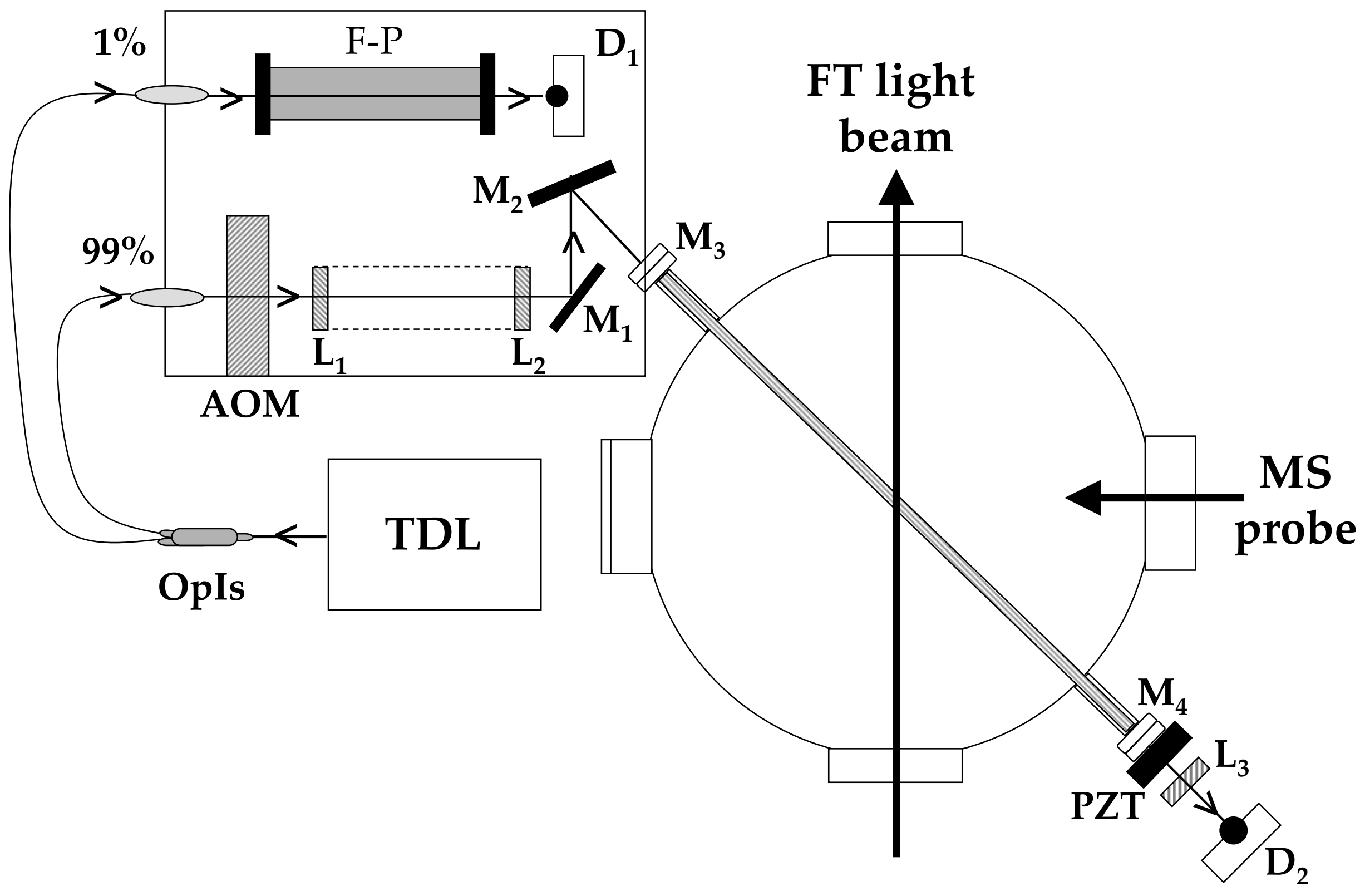




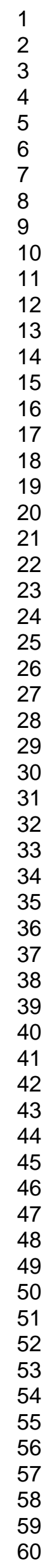

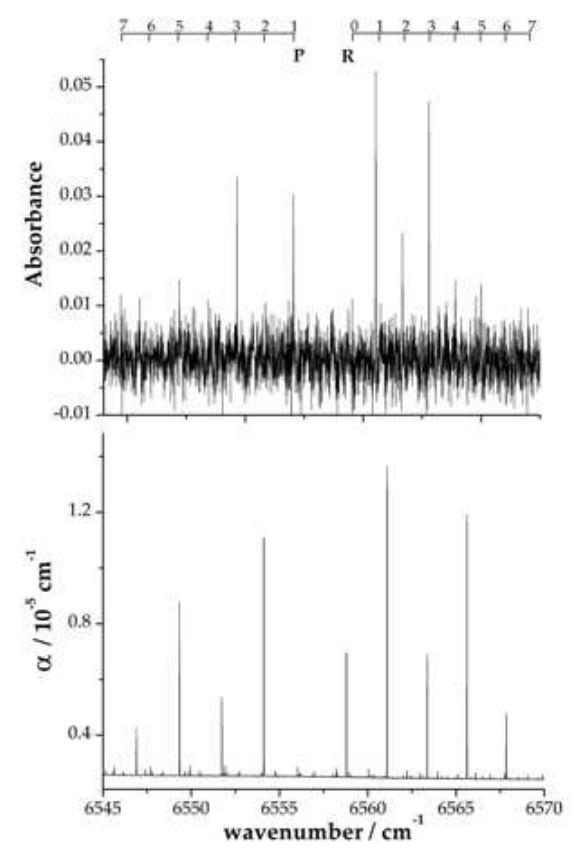

$254 \times 190 \mathrm{~mm}(72 \times 72 \mathrm{DPI})$

URL: http://mc.manuscriptcentral.com/tandf/tmph 


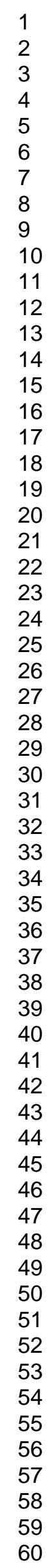

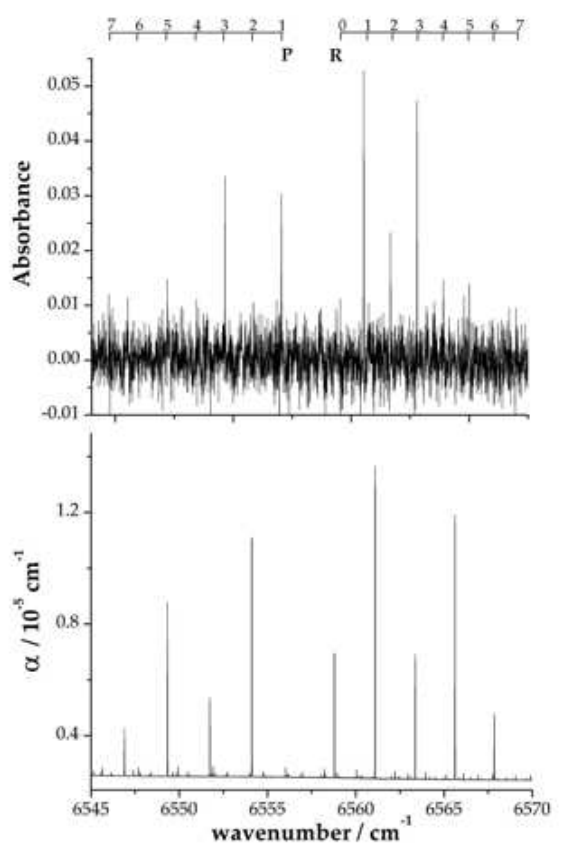

$254 \times 190 \mathrm{~mm}(72 \times 72 \mathrm{DPI})$

URL: http://mc.manuscriptcentral.com/tandf/tmph 


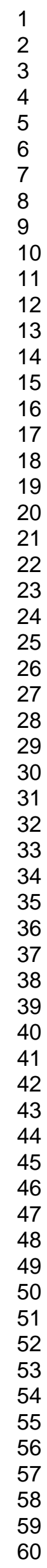

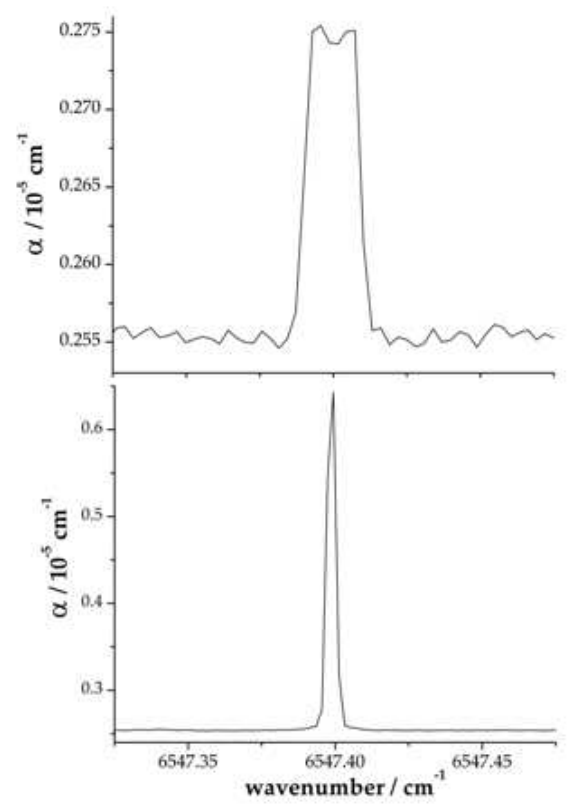

$254 \times 190 \mathrm{~mm}(72 \times 72 \mathrm{DPI})$

URL: http://mc.manuscriptcentral.com/tandf/tmph 


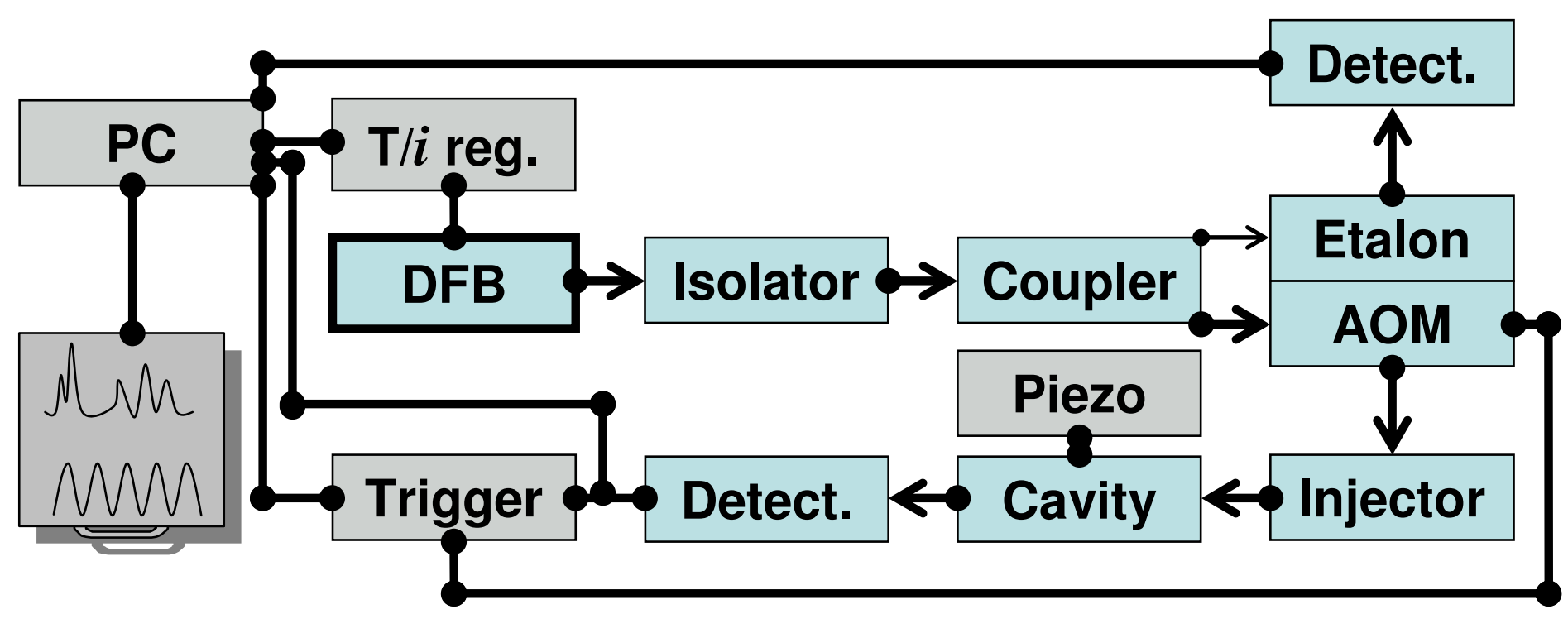

Figure 9, Herman et al. 